\title{
PEMETAAN KURIKULUM PROGRAM STUDI PENDIDIKAN TEKNIK ELEKTRO FAKULTAS TEKNIK UNIVERSITAS NEGERI PADANG UNTUK MEMAKSIMALKAN KOMPETENSI LULUSAN
}

\author{
Media Syafrina Putri ${ }^{1}$, Mukhlidi Muskhir ${ }^{2}$ \\ ${ }^{1,2}$ Pendidikan Teknik Elektro, Fakultas Teknik, Universitas Negeri Padang \\ ${ }^{1}$ mediasyafrinaputri@gmail.com
}

\begin{abstract}
Abstrak
Penelitian ini membahas tentang pemetaan kurikulum Program Studi Pendidikan Teknik Elektro, Fakultas Teknik, Universitas Negeri Padang untuk memaksimalkan kompetensi lulusan. Pemetaan kurikulum Program Studi Pendidikan Teknik Elektro dilakukan agar adanya hubungan yang koheren antara materi yang di ajarkan dengan harapan mahasiswa. Tujuan penelitian ini adalah untuk memetakan kurikulum PSPTE-FT UNP yang mengacu standar kompetensi, ketika kurikulumya tertata sesuai kebutuhan mahasiswa maka akan mudah bagi program studi untuk menghasilkan lulusan yang berkompetensi yang siap bersaing di dunia kerja. Hasil penelitian menunjukkan, dengan menyelesaikan 53 mata kuliah dengan bobot 145 SKS mahasiswa bisa mendapatkan gelar sarjana, di dalamnya termasuk mengerjakan skripsi pada semester akhir. Dengan urutan seminar proposal dan sidang hasil penelitian skrisi. Sebelum penelitian dilakukan, mahasiswa mendapat gelar sarjana dengan menyelesaikan 56 mata kuliah dengan bobot 145 SKS. Namun pada kurikulum ada 3 mata kuliah yang tidak diselesaikan. Dari hasil penelitian dapat disimpulkan bahwa dengan 53 mata kuliah dengan 145 SKS lebih baik daripada 56 mata kuliah dengan bobot 145 SKS.
\end{abstract}

Kata Kunci: Program Studi Pendidikan Teknik Elektro, pemetaan kurikulum, SKS, kurikulum, mata kuliah.

\begin{abstract}
This research is about mapping curriculum of Electrical Engineering Education Program, Faculty of Engineering, State University of Padang. The curriculum mapping program of Electrical Engineering Education Studies is conducted so that there is a coherent relationship between the material being taught and the student's expectation. The purpose of this research is to map the curriculum of PSPTE-FT UNP that characterize the standard of competence, mix the curriculum arranged according to the requirement of the student it will be easy for the study program to produce competent graduates who are ready to compete in work world. The results showed, with 53 sheets of courses with a weight of 145 credits students can get a bachelor degree, in it including doing thesis in the final semester. With the sequence of proposal seminars and trial sessions of research results. Prior to the research, students received a bachelor's degree with a volume of 56 courses weighing 145 credits. But in the curriculum there are 3 courses that are not resolved. From the research results can be concluded with 53 courses with 145 credits better 56 courses weighing 145 credits.
\end{abstract}

Keywords: Electrical Engineering Education courses, curriculum mapping, SKS, curriculum, course.

Received date 30/11/2019, Revised date 9/12/2019, Accepted date 07/01/2020 


\section{PENDAhULUAN}

Pendidikan vokasi merupakan jenjang pendidikan yang selalu dinamis dalam melakukan perubahan kurikulum pendidikan sesuai dengan pertumbuhan pasar kerja dan beradaptasi dengan perkembangan ilmu pengetahuan dan teknologi. Hal ini berarti pendidikan vokasi akan selalu mengalami pergeseran paradigma.Pendidikan memiliki peran penting dalam meningkatkan kualitas seseorang dalam persaingan global. Pendidikan yang dilakukan secara berkelanjutan sangat penting untuk mencapai hasil yang memuaskan.

Pada kehidupan sekarang ini semua orang berkepentingan terhadap jalannya pendidikan karena pendidikan merupakan wadah pembinaan tenaga kerja, dapat menambah lapangan pekerjaan, serta untuk memperoleh status tertentu dalam masyarakat. Seiring berkembangnya zaman setiap perguruan tinggi melakukan perubahan kurikulum. Perubahan kurikulum di perguruan tinggi merupakan aktivitas rutin yang harus dilakukan sebagai tanggapan terhadap perkembangan IPTEK, kebutuhan masyarakat, serta kebutuhan pengguna lulusan (stakeholder need). [1] Kurikulum digunakan untuk acuan pengalaman pembelajaran siswa, diperlihatkan dalam pembentukan tujuan, rencana, dan rancangan untuk pembelajaran dan pengimplementasian dari rencana-rencana tersebut dan rancangan dalam lingkungan sekolah. Sementara [2] menjelaskan bahwa kurikulum adalah suatu rencana yang disusun untuk melancarkan proses belajar-mengajar di bawah bimbingan dan tanggung-jawab sekolah atau lembaga pendidikan besrta staf pengajarnya.

Lulusan yang akan memasuki dunia kerja merupakan lulusan yang berkompetensi. Secara umum kompetensi merupakan penguasaan pengetahuan, keterampilan dan kemampuan yang dapat diwujudkan oleh perilaku-perilaku kognitif, afektif dan psikomotori dengan sebaik-baiknya. [3]. Selaras dengan pendapat diatas, [4] mengemukakan bahwa kompetensi merupakan pengetahuan, kemampuan dan keahlian (keterampilan) yang dimiliki seseorang yang secara langsung mempengaruhi kinerjanya 
Berdasarkan Peraturan Pemerintah RI nomor 19 tahun 2009, Pasal 25, standar kompetensi lulusan mencakup sikap, pengetahuan, dan keterampilan. Kemudian pasal 26 menyatakan bahwa standar kompetensi lulusan pada jenjang perguruan tinggi (PT) bertujuan untuak mempersiapkan peserta didik yang berakhlak mulia, memiliki pengetahuan, keterampilan, kemandirian, dan sikap untuk menemukan, mengembangkan serta menerapkan ilmu, teknologi dan seni yang bermanfaat bagi kemanusiaan. Dengan demikian dalam pemetaan kurikulum program studi pendidikan teknik elektro perlu diperhatikan mata kuliah dalam ranah sikap, pengetahuan, dan keterampilan.

SDM merupakan salah satu faktor penentu terpenting dalam mencapai keberhasilan program pembangunan. SDM yang berkualitas akan mampu mengelola sumber daya alam dengan baik dan efisien. Masalah SDM tidak bisa lepas dari masalah tenaga kerja. Kualitas tenaga kerja sangat tergantung pada kualitas SDM. Oleh karena itu, kualitas SDM harus mendapatkan prioritas utama untuk ditingkatkan dan dikembangkan guna mendapatkan kualitas tenaga kerja yang baik. Tenaga kerja yang berkualitas dan memiliki etos kerja yang tinggi akan memperkuat posisi industri yang pada akhirnya akan mempekuat perekonomian negara.

Lulusan program studi pendidikan teknik elektro terdapat empat profil lulusan yaitu : calon pendidik, fasilisator pembelajaran pembelajaran kreatif dan inovatif yang mendidik dengan penguasaan materi teknik elektro yang baik, memiliki kemampuan menggunakan teknologi informasi untuk mengikuti perkembangan ilmu teknik elektro dan pembelajarannya, instruktur pada Balai Latihan Keterampilan di dunia industri/usaha yang menguasai materi teknik elektro dengan baik memiliki kemampuan menggunakan teknologi informasi untuk mengikuti perkembangan dunia industri/usaha, calon pengelola lembaga pendidikan vokasi bimbingan belajar/satuan pendidikan negeri maupun swasta, mampu berwirausaha bekerja mandiri dan bekerjasama dalam bidang teknik elektro. 
Tujuan penelitian ini adalah untuk memetakan kurikulum PSPTE-FT UNP yang mengacu standar kompetensi, ketika kurikulumya tertata sesuai kebutuhan mahasiswa maka akan mudah bagi program studi untuk menghasilkan lulusan yang berkompetensi yang siap bersaing di dunia kerja.

\section{METODA}

Jenis penelitian ini adalah penelitian kualitatif dengan menggunakan pendekatan deskriptif. Metode penelitian kualitatif sering disebut metode penelitian naturalistik karena penelitiannya dilakukan pada kondisi yang alamiah [5]. Penelitian tentang pemetaan kurikulum dilaksanakan di Universitas Negeri Padang, tepatnya di Fakultas Teknik Prodi Pendidikan Teknik Elektro. Prodi Pendidikan Teknik Elektro merupakan salah satu Prodi yang melakukan rekontruksi kurikulum menuju akreditasi ASEAN.

Teknik pengumpulan data yang digunakan dalam penelitian ini adalah teknik observasi, teknik wawancara, dan dokumentasi. Berikut ini akan dijelaskan teknik-teknik pengumpulan data yang digunakan oleh peneliti sebagai berikut. Dengan observasi secara langsung, peneliti dapat memahami konteks data dalam berbagai situasi, maksudnya dapat memperoleh pandangan secara menyeluruh. Keberhasilan observasi sebagai teknik pengumpulan data sangat bergantung pada peneliti sebab peneliti melihat, mendengar, dan mengamati langsung kemudian menyimpulkannya [6]. Dokumentasi merupakan pengumpulan data oleh peneliti dengan cara mengumpulkan dokumen-dokumen dari sumber terpercaya yang berkaitan dengan profil lulusan dan pengguna lulusan (stakeholders. Metode dokumentasi menurut yaitu mencari data mengenai variabel yang berupa catatan, transkrip, buku, surat kabar, majalah, prasasti, notulen rapat, agenda dan sebagainya.

\section{HASIL DAN PEMBAHASAN}

Pemetaan kurikulum Program Studi Pendidikan Teknik Elektro dilakukan agar adanya hubungan yang koheren antara materi yang di ajarkan dengan harapan mahasiswa. Secara umum, kurikulum yang koheren adalah (1) dirancang dengan 
baik dan dirancang dengan sengaja untuk memfasilitasi pembelajaran, (2) bebas dari kesenjangan akademis dan pengulangan yang tidak perlu, dan (3) selaras dengan pelajaran, kursus, bidang studi, dan tingkat kelas. Ketika pendidik memetakan kurikulum, mereka berupaya memastikan bahwa apa yang sebenarnya diajarkan kepada siswa sesuai dengan harapan akademis di bidang subjek atau tingkat kelas tertentu. Ketika kurikulum Program Studi Pendidikan Teknik Elektro sudah baik, maka akan terlihat pada lulusannya.

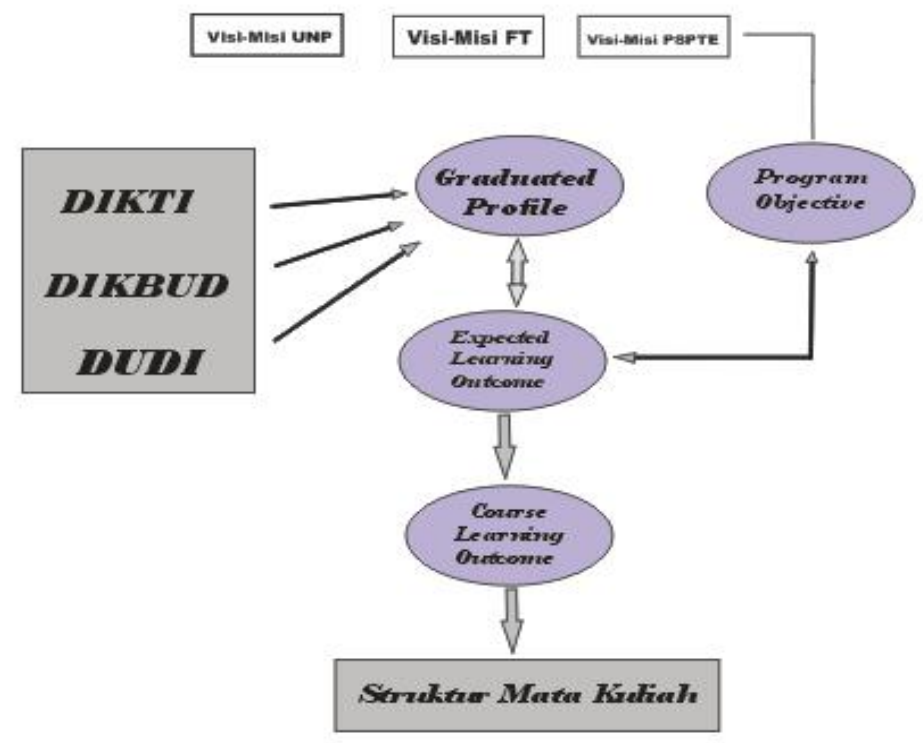

Gambar 1. Diagram Alir Penyusunan Kurikulum PSPTE

Untuk memenuhi visi, misi, sasaran, dan tujuan yang telah dirumuskan, secara keseluruhan Kurikulum Program Sarjana (S1) Program Studi Pendidikan Teknik Elektro terdiri dari 145 SKS dengan 53 mata kuliah.:

Tabel 1. Jumlah SKS Mata Kuliah Tiap Semesternya

\begin{tabular}{|c|c|c|}
\hline No & Semester & Jumlah SKS \\
\hline 1 & I & 22 \\
\hline 2 & II & 22 \\
\hline 3 & III & 22 \\
\hline 4 & IV & 19 \\
\hline 5 & V & 22 \\
\hline 6 & VI & 20 \\
\hline 7 & VII & 8 \\
\hline 8 & VIII & 10 \\
\hline
\end{tabular}




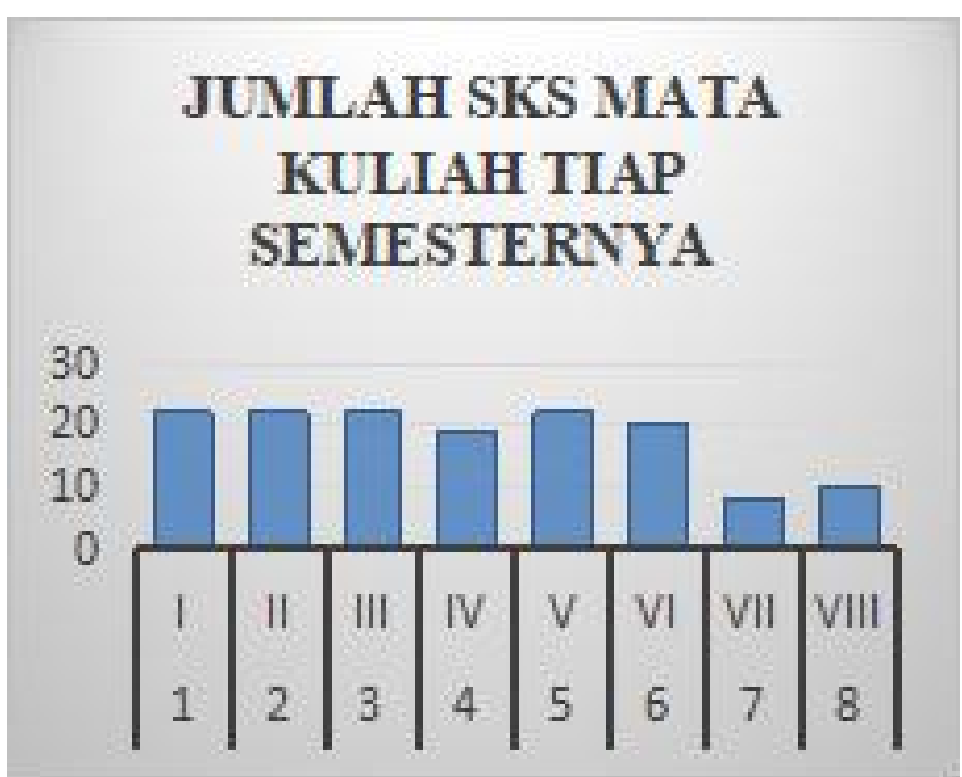

\section{Gambar 2. Grafik Jumlah SKS Mata Kuliah PSPTE tiap Semestern}

Pemetaan kurikulum yang dilakukan sama halnya dengan pemetaan mata kuliah yang ada tiap semesternya. Pemetaan kurikulum ini dilakukan guna meningkatkan kompetensi dari lulusan program studi, karena apabila kurikulum sebuah program studi itu jelas maka program studi tersebut dapat menghasilkan lulusan yang berkompetensi yang bisa bersaing di dunia pekerjaan.

Sebelum di Rekontruksi, untuk Prodi Pendidikan Teknik Elektro program studi menyediakan 61 mata kuliah dengan 154 SKS. SKS yang dimaksud yaitu sistem kredit semester. Mahasiswa mendapatkan sebanyak 154 SKS untuk mendapat gelar sarjana. Dari 154 SKS, mahasiswa harus menyelesaikan minimal 150 SKS, karena di antara 61 mata kuliah tersebut terdapat 3 mata kuliah pilihan sebanyak 6 SKS (2 SKS/semesternya) hanya di hitung 2 SKS saja di antaranya yaitu mata kuliah Bahasa Inggris, Ilmu Sosial dan Budaya dasar, ilmu kealaman dasar. Jadi total yang harus diselesaikan mahasiswa adalah 59 mata kuliah dengan 150 SKS.

Pada kenyataan yang ada, dengan 56 mata kuliah yang berbobot 145 SKS, mahasiswa sudah bisa mendapat gelar sarjana. Di antara 59 mata kuliah ada 3 mata kuliah yang belum ada kepastiannya untuk diselesaikan, yaitu mata kuliah magang observasi sekolah dengan bobot 1 sks, dan magang perangkat pembelajaran dengan bobot 2 sks dan magang praktek mengajar 2 sks. 
Setelah di rekontruksi, Program Studi Pendidikan Teknik Elektro menyediakan 145 SKS dengan 53 mata kuliah. Dengan bobot tersebut mahasiswa dapat mendapatkan gelar sarjana. Agar mahasiswa mempunyai kompetensi dalam meneliti diberikan mata kuliah yang mendukung pada pencapaian kompetensi tersebut, seperti fllsafat ilmu, metodologi penelitian pendidikan, komunikasi ilmiah dan statistika sederhana. Keempat mata kuliah ini terkait satu dengan lainnya secara bersinergi dengan meletakkan penguasaan kemampuan epistemologis dalam menyusun proposal penelitian dan penyelesaian skripsi.

Skripsi merupakan sebagian persyaratan yang dapat dipilih untuk mendapatkan gelar sarjana pendidikan dan penyelesaiannya diarahkan oleh suatu proses bimbingan. Proses bimbingan tidak semata-mata dilakukan oleh perseorangan, melainkan oleh sistem yang melembaga. Guna memudahkan pelayanan dan meningkatkan kualitas, maka dibentuk komisi skripsi. Komisi skripsi ini terdiri dari satu dosen pembimbing dengan dua dosen pengarah/penguji. Dengan alur mahasiswa menyelesaikan bab 1-3 kemudian melaksanakan seminar proposal penelitian, dilanjutkan penelitian kemudian melengkapi skripsi sampai bab 5 lalu melaksanakan ujian skripsi, setelah itu barulah mahasiswa mendapatkan gelar sarjananya. Bagi mahasiswa yang memilih tugas akhir selain skripsi, maka wajib menempuh mata kuliah pengganti skripsi yang berbobot 6 SKS.

\section{SIMPULAN DAN SARAN}

Berdasarkan hasil analisis data penelitian yang telah dilakukan, untuk melakukan pemetaan kurikulum Program Studi Pendidikan Teknik Elektro (PSPTE), banyak yang perlu diperhatikan agar kurikulum tersebut tertata rapi dengan jelas. Untuk melakukan pemetaan kurikulum Program Studi Pendidikan Teknik Elektro (PSPTE), beberapa hal yang perlu diperhatikan yaitu, efeknya apabila lulusan banyak yang diterima stakeholders maka berkurang angka pengangguran terhadap lulusan program studi tersebut, pengguna lulusan (stakeholders) dari PSPTE yaitu terdiri dari KEMENDIKBUD, KEMENRISTEKDIKTI, dan DUDI. Dimana profil lulusan yang ada yaitu 
sebagai pendidik, sebagai tenaga kependidikan, sebagai tenaga ahli di bidang teknik elektro, dan sebagai enterpreneurship dan mahasiswa yang ingin mendapatkan gelar sarjana harus menyelesaikan mata kuliah dengan bobot 145 SKS dengan 53 mata kuliah. Diantaranya termasuk menyelesaikan Skripsi.

Hasil penelitian ini memberikan beberapa saran yaitu: pemetaan kurikulum PSPTE harus dirumuskan dengan jelas dan pasti, agar pelaksanaan kurikulum dilaksanakan dengan baik dan tidak rancu. Apabila dari kurikulum saja sudah bagus maka lulusannya juga pasti bagus sehingga PSPTE dapat menghasilkan lulusan yang berkompetensi, penerapan kurikulum PSPTE harus terus dikembangkan dan di evaluasi untuk peningkatan kualitas lulusannya, untuk peneliti lainnya, dikarenakan penelitian ini masih belum selesai secara lengkap, maka peneliti dapat melakukan analisis yang tepat tentang pemetaan kurikulum yang dibutuhkan oleh lulusan sehingga menjadi acuan yang benar dalam kegiatan belajar-mengajar.

\section{REFERENSI}

[1] Perdana, D. I. (2013). Kurikulum Dan Pendidikan Di Indonesia Proses Mencari Arah Pendidikan Yang Ideal Di Indonesia atau Hegemoni Kepentingan Penguasa Semata?. Jurnal Pemikiran Sosiologi, 2(1), 63-74.

[2] Nasution, S. 2008. Kurikulum dan Pengajaran. Bumi Aksara.

[3] McAshan, H. H. (1981). Competency-based education and behavioral objectives. Eaglewood Cliffs, NJ: Educational Technology Publications, Inc.

[4] Yuniarsih, T., \& Suwatno. (2009). Manajemen Sumber Daya Manusia untuk Perusahaan Dari Teori ke Praktik. Jakarta: PT. Raja Grafindo Persada.

[5] Sugiyono.(2013). Cara Mudah Menyusun: Skripsi, Tesis, dan Disertasi. Bandung Alfabeta.

[6] Arikunto, S. (2013). Prosedur Penelitian: Suatu Pendekatan Praktik. Jakarta: Rineka Cipta. 